\title{
Imaging diseases of the aorta by MRI: a cost- effectiveness analysis of contrast-enhanced studies compared to non-contrast enhanced angiographic studies
}

\author{
Emer Sonnex*, Melissa L Grzeszczak, Richard Coulden
}

From 15th Annual SCMR Scientific Sessions

Orlando, FL, USA. 2-5 February 2012

\section{Summary}

Non-contrast-enhanced MR angiography (MRA) of the aorta is a robust alternative to using contrast-enhanced (CE) angiography in the imaging of thoracic aortic diseases. What is the cost impact of not using intravenous contrast routinely in thoracic aorta MRA?

\section{Background}

Free-breathing, ECG-triggered, navigator-gated 3D segmented steady state free precession (SSFP) MRA is a promising MR technique for imaging the thoracic aorta. We wanted to establish the economic impact of using non-contrast enhanced angiography (non-CEMRA) in our unit compared to the same time period last year when only CEMRA was used.

\section{Methods}

Over a 3 month period, $22 \%$ of referrals to our cardiac MRI unit (Siemens Aera $\odot$, Erlangen, Germany) were for diseases of the aorta. These patients were divided into 5 subsets: 1) familial screening (Marfans, Turners, etc), 2) dilatation, 3) follow-up aortic dissection, 4) congenital aortic and valve disease \& 5) vasculitis. 80 data sets for patients referred for evaluation of their aorta were examined. These were compared with 80 data sets in patients with aortic disease imaged in a similar period when only CEMRA was available. Clinical evaluation included recording the patients' serum creatinine, correlation with aortic measurements from previous imaging studies and subjective assessment of image quality. Cost analysis included costs of contrast agent, power injector

Diagnostic Imaging, University of Alberta Hospitals, Edmonton, AB, Canada sets and routine consumable costs associated with intravenous access.

\section{Results}

The unit price for consumables for thoracic aortic CEMRA was estimated at \$140CAD*/patient (\$110CAD for Gadolinium and \$30CAD for other disposables). Vasculitis patients (group 5) were excluded from both data sets as intravenous contrast was needed for delayed enhancement imaging. No patient was excluded from $\mathrm{CE}$-angiography due to a high serum creatinine (eGFR in all patients $\geq 30 \mathrm{mls} / \mathrm{min}$ ). No patient undergoing non-CEMRA required an additional CEMRA for a nondiagnostic study. We examined 75 data sets in the 'prenavigator' group and 72 in the 'post-navigator' group. In the pre-navigator group, 50 patients (67\%) underwent CEMRA as part of their examination: $9 / 12$ (75\%) group $1,12 / 28$ (43\%) group 2, 2/3 (67\%) group 3 and 27/32 (84\%) group 4 . In the post-navigator group, 14 patients (19\%) underwent CEMRA: 5/18 (28\%) group 1 (268\% reduction), $6 / 31$ (19\%) group 2 (266\% reduction), $1 / 5$ (20\%) group 3 (335\% reduction) and 5/18 (28\%) group 4 (300\% reduction). Costs associated directly with CEMRA in the pre-navigator group were \$7000CAD (50 $\mathrm{x} \$ 140 \mathrm{CAD}$ ) and in the post-navigator group were \$1960CAD (14 x \$140CAD), a saving of \$5040.

"CAD = Canadian dollars.

\section{Conclusions}

We conclude that using a free-breathing, ECG-triggered, navigator-gated 3D segmented steady state free precession (SSFP) sequence is a cost-effective way of imaging 
Table 1 Number of CEMRA performed

\begin{tabular}{lccccr}
\hline & Group 1 familial screening & Group 2 dilatation & Group 3 dissection & Group 4 aortic congenital disease & Group 5 vasculitis \\
\hline Pre-navigator & $9 / 12(75 \%)$ & $12 / 28(43 \%)$ & $2 / 3(67 \%)$ & $27 / 32(84 \%)$ & $5 / 5(100 \%)$ \\
Post-navigator & $5 / 18(28 \%)$ & $6 / 31(19 \%)$ & $1 / 5(20 \%)$ & $5 / 18(28 \%)$ & $8 / 8(100 \%)$ \\
$\%$ reduction & $268 \%$ & $226 \%$ & $335 \%$ & $300 \%$ & not applicable \\
\hline
\end{tabular}

disease of the aorta without compromising imaging quality.

\section{Funding}

Not applicable.

Published: 1 February 2012

doi:10.1186/1532-429X-14-S1-P45

Cite this article as: Sonnex et al:: Imaging diseases of the aorta by MRI: a cost-effectiveness analysis of contrast-enhanced studies compared to non-contrast enhanced angiographic studies. Journal of Cardiovascular Magnetic Resonance 2012 14(Suppl 1):P45.

Submit your next manuscript to BioMed Central and take full advantage of:

- Convenient online submission

- Thorough peer review

- No space constraints or color figure charges

- Immediate publication on acceptance

- Inclusion in PubMed, CAS, Scopus and Google Scholar

- Research which is freely available for redistribution

Submit your manuscript at www.biomedcentral.com/submit 